\title{
Euplocania cearaensis Silva-Neto, García Aldrete \& Rafael, 2019 (Psocodea, 'Psocoptera', Ptiloneuridae): description of the female, update of the diagnosis and variation in the wing venation
}

\author{
Natália S. Reategui ${ }^{(\oplus,}$, Alberto M. Silva-Neto ${ }^{ \pm 0}$, José A. Rafael(
}

Instituto Nacional de Pesquisas da Amazônia - INPA, Manaus, Amazonas, Brazil.

表牛Corresponding author: bio.alberto@gmail.com

Edited by: Daniell R. R. Fernandes

Received: October 22, 2020. Accepted: November 06, 2020. Published: December 15, 2020.

Abstract. The female of Euplocania cearaensis Silva-Neto, García Aldrete \& Rafael, 2019 is described and illustrated, new records on variation in the fore and hind wings venation and an update of the diagnosis are provided. The material of this study where from two localities in the Parque Nacional de Ubajara, Ubajara, Ceará, Brazil.

Keywords: Epipsocetae, psocids, neotropics, taxonomy.

Euplocania Enderlein, 1910 is one of 12 recent genera in the psocopteran family Ptiloneuridae. It presently includes forty-seven recognized species, with twenty-five species known only from males, four species known only from females, and eighteen species known from both sexes; these species occur in Nicaragua, Colombia, Peru, Brazil, Ecuador and Paraguay (Silva-Neto et al. 2019). Brazil is the second-richest country for Euplocania species, with sixteen species distributed in five Brazilian States (Silva-Neto \& García Aldrete 2020). Only four of these Euplocania species registered in Brazil have the female described (Euplocania badonneli New \& Thornton, 1988; Euplocania cerata New, 1980; Euplocania marginata New \& Thornton, 1988 and Euplocania quinquedivisa Silva-Neto, García Aldrete \& Rafael, 2019).

Euplocania cearaensis Silva-Neto, García Aldrete \& Rafael, 2019 was described on basis of a male specimen collected in a Malaise trap located in the Parque Nacional de Ubajara, Ubajara, Ceará, Brazil. One of us (NSR) recently found in a miscellany of insects preserved in $80 \%$ ethanol, at the Instituto Nacional de Pesquisas da Amazônia, in Manaus, Amazonas, Brazil (INPA), forty-eight male specimens of E. cearaensis and nine female specimens (Fig. 1) associated with this species. The purpose of this paper is to describe and illustrate the female of $E$. cearaenis, to present an updated diagnosis to this species, including female characters and to describe the variation of the forehindwing venation.

A total of fifty-seven specimens were available for study. They were dissected in $80 \%$ ethanol, and their parts were mounted on slides in Canada balsam. Standard measurements (in $\mu \mathrm{m}$ ) were taken with a filar micrometer. Abbreviations of parts measured are as follows: FW and $\mathrm{HW}$ : right fore- and hind- wing lengths; $F, T, t 1, t 2$ and $t 3$ : lengths of femur, tibia and tarsomeres 1, 2 and 3 of right hind leg; $\mathrm{f} 1 . . . \mathrm{fn}$ : lengths of flagellomeres $1 . . . n$ of right antenna; $M \times 4$ : length of fourth segment of right maxillary palpus; IO: minimum distance between compound eyes in dorsal view of head; $\mathrm{D}$ and $\mathrm{d}$ : antero-posterior and transverse diameter, respectively, of right compound eye in dorsal view of head; PO: $d / D$.

The specimens studied were stored in $C D$ boxes, as described by Silva-Neto et al. (2016). Photographs of the parts mounted were taken with a Leica DFC500 digital camera attached to a Leica M205C stereomicroscope, connected to a computer with the Leica Application Suite LAS V3.6 software, which includes an Auto-Montage module
(Syncroscopy software). The specimens will be deposited in the Invertebrate Collection of the Instituto Nacional de Pesquisas da Amazônia, in Manaus, Amazonas, Brazil (INPA) and in the Entomological Collection of the Museu Nacional do Rio de Janeiro, Rio de Janeiro, Brazil (MNRJ).

\section{Euplocania cearaensis Silva-Neto, García Aldrete \& Rafael, 2019}

(Figs. 1-14)

Updated diagnosis. Forewings with a marginal pigmented band from $R_{4+5}$ to $A_{2}$ with two hyaline areas, boomerang shaped, on each side of the distal ends of the veins at wing margin and two or three brown spots just below the $A_{1}$ (Figs. 3, 13). Hypandrium of three sclerites (Fig. 13 in Silva-Neto et al. 2019), central sclerite, with two posterior projections sinuous, distally curved outwards and acuminate, flanking a short median area almost straight; phallosome (Fig. 14 in Silva-Neto et al. 2019) with mesal sclerite wide transversely, strongly sclerotized, anteriorly sinuous, posteriorly with a long median projection, blunt ended, three pairs of endophallic sclerites, antero-mesal pair strongly sclerotized, rounded basally, almost square posteriorly, with acuminate apex; antero-lateral pair stout, elongate, proximally wide, narrowing posteriorly, distally acuminate; posterior pair emerging from behind the mesal sclerite, small, slightly curved outward. Ninth sternum (Fig. 7) almost elliptical, with an anterior area with a transverse pair of arched sutures in the middle and with a convex pigmented area, arcshaped, a mesal area narrow, with a small deeply cleft, V-shaped, in the central area, a posterior area convex in the middle. Gonapophyses with $v 2+3$ proximally with elongated pointed proximal heel, with five setae on v3 (Fig. 8).

\section{Description}

Male. As described by Silva-Neto et al. (2019).

Female. Color. Compound eyes black, ocelli hyaline, with ochre centripetal crescents, head pattern (Figs. 1, 2). Scape dark brown, pedicel pale yellow, $\mathrm{f1}-\mathrm{f} 3$ brown, with apex pale yellow. $\mathrm{Mx} 4$ yellow with apex dark brown. Legs with coxae, trochanters and femora brown, tibiae yellow with apex dark brown; tarsomere 1 yellow with end dark brown, tarsomeres 2-3 dark brown. Forewings (Fig. 3) veins brown, with a dark brown spot distally at wing margin, a marginal pigmented 
band from $R_{4+5}$ to $A_{2}$ with two hyaline areas, boomerang shaped, on each side of the distal ends of the veins at wing margin; Rs and cross vein Rs-M dark brown, pterostigma dark brown, with a hyaline window, almost elliptical at lower angle. Hindwings (Fig. 4), almost hyaline, veins brown, each with a brown spot distally at wing margin.

Morphology. Head with vertex concave in the middle, slightly above the level of the upper border of the compound eyes, these without interommatidial setae (Fig. 2). Outer cusp of lacinial tip broad, with eight denticles (Fig. 5). Forewing pterostigma almost triangular, areola postica tall, with round apex, slanted posteriorly, M stem slightly concave proximally, then almost straight, with four primary branches, $M_{1}$ almost straight, $M_{2}-M_{4}$ sinuous (Fig. 3). Hindwing Rs straight, $R_{2+3}$ straight, $R_{4+5}$ slightly convex in the middle, $M$ sinuous (Fig. 4). Subgenital plate broad, wide basally, with sides converging towards a triangular posterior border, pigmented area wide, U- shaped, setae as illustrated (Fig. 6). Ninth sternum (Fig. 7) broad, elliptical, anteriorly almost straight, with three distinct areas, an anterior area with a transverse pair of arched sutures in the middle and with a convex pigmented area, arc-shaped, a mesal area narrow, concave in the middle, with convex
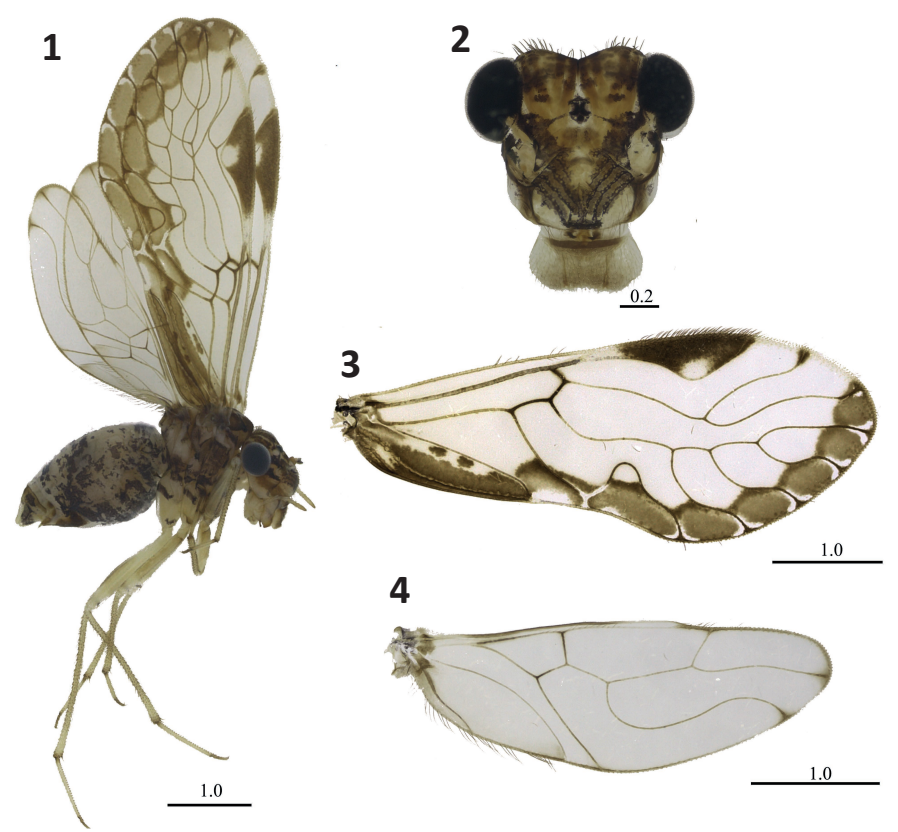

Figures 1-4. Euplocania cearaensis Silva-Neto, García Aldrete \& Rafael (female specimen). 1. Habitus lateral view. 2. Front view of head. 3. Left forewing. 4. Left hind wing. Scales in $\mathrm{mm}$.
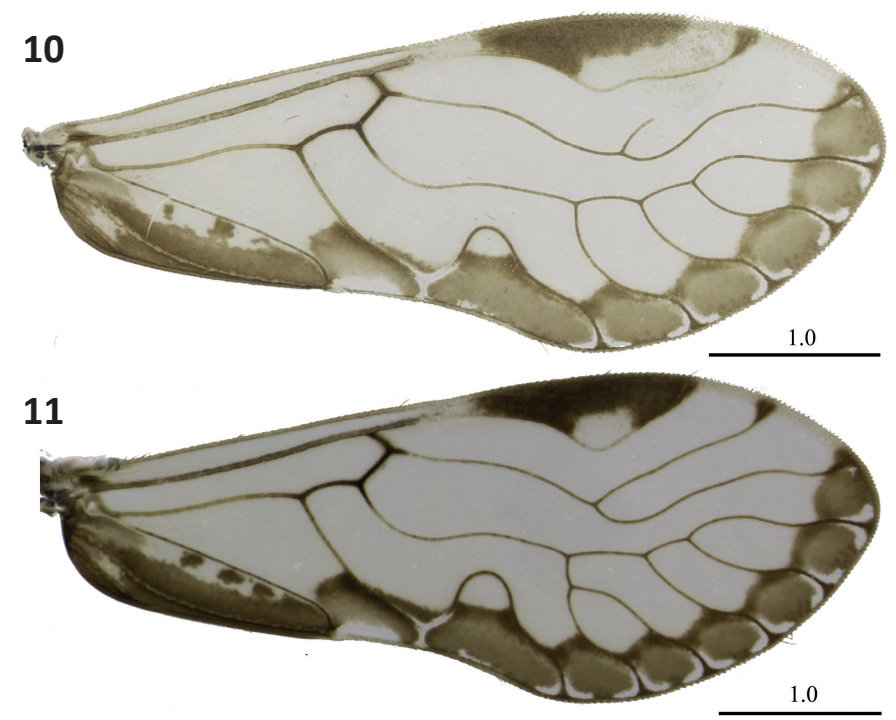

Figures 10-11. Variations of venation of forewings in two different females of Euplocania cearaensis Silva-Neto, García Aldrete \& Rafael. 10. Right forewing. 11. Left forewing. Scales in $\mathrm{mm}$. sides, with a small deeply cleft, V-shaped, in the middle, a posterior area without pigmented bands, posteriorly convex in the middle. Gonapophyses with v1 slender, heavily sclerotized, distally acuminate, v2+3 stout, proximally wide, with long, almost triangular heel, pointed, five setae on v3 as illustrated, distal process slender, acuminate, with a field of microsetae (Fig. 8). Epiproct triangular, anteriorly with sinuous edges, with three mesal setae, other setae as illustrated (Fig. 9). Paraprocts almost triangular, broad, anteriorly concave in the middle, sensory fields with 32 trichobothria on basal rosettes; setae as illustrated (Fig. 9).

Measurements (in microns). FW: 4971, HW: 3355, F: 1256, T: 2068, t1: 849, t2: 106, t3: 178, f1: 877, f2: 785, f3: 768, Mx4: 322, IO: 577, D: 436, d: 295, PO: 0.68.

Variation in the fore-hindwing venation. 1 female with right forewing Pterostigma posteriorly more elongated and with color different from the standard, $R_{2+3}$ unfinished, as a spur-vein (Fig. 10). 1 female with left forewing $M_{4}$ vein branched resulting in $M_{4 a}$ and $M_{4 b}$ (Fig. 11). 1 male (Fig. 12) with left hindwing with $M$ vein branched resulting in $M_{1}$ and $M_{2}$ (Fig. 14).

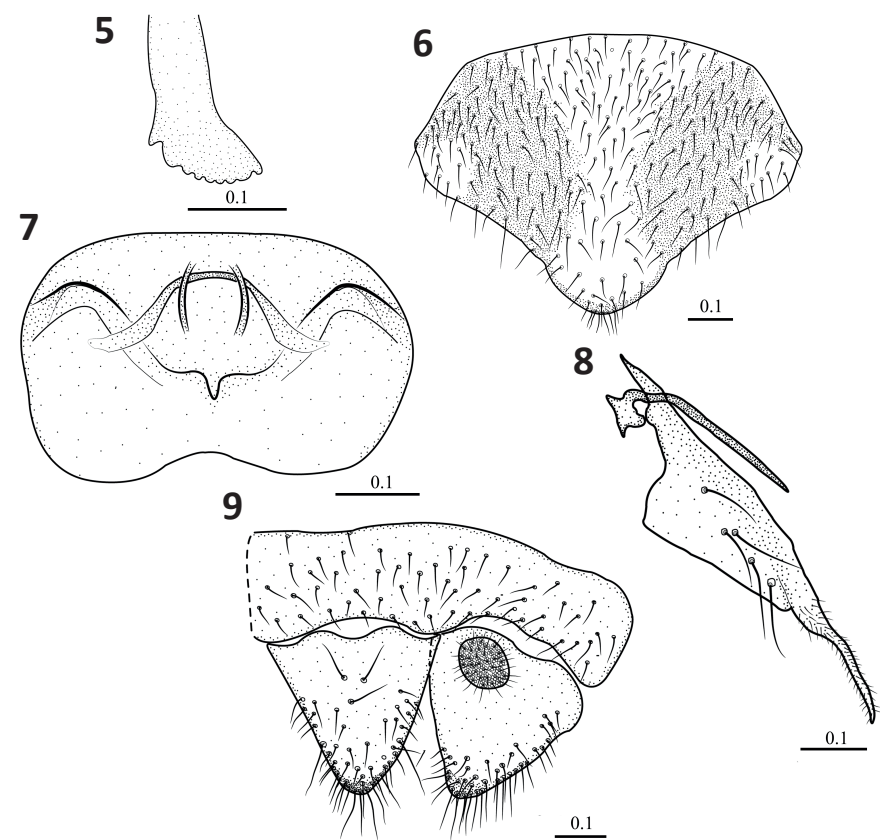

Figures 5-9. Euplocania cearaensis Silva-Neto, García Aldrete \& Rafael (female specimen). 5. Lacinial tip. 6. Subgenital plate. 7. Ninth sternum. 8. Right gonapophyses. 9. Clunium, right paraproct and epiproct. Scales in $\mathrm{mm}$.

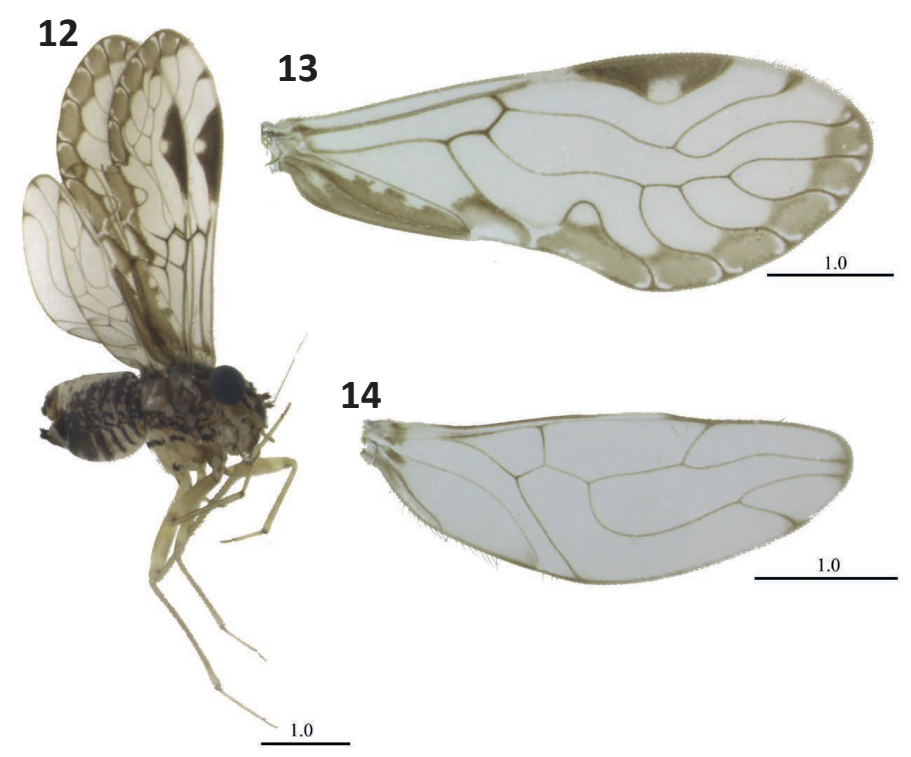

Figures 12-14. Male specimen of Euplocania cearaensis Silva-Neto, García Aldrete \& Rafael. 12. Habitus lateral view. 13. Left forewing. 14. Left hindwing with variation in venation. Scales in $\mathrm{mm}$. 
Material examined. 32 males (INPA), 6 males (MNRJ), 6 females (INPA) and 1 female (MNRJ), BRAZIL, Ceará, Ubajara, Parque Nacional de Ubajara, Trilha Araticum, Rio das Minas na altura da trilha do

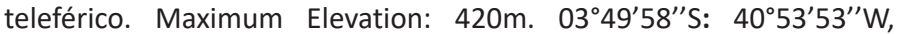
14.ii.2013, Malaise trap, Santos, A.P.M, Takiya D.M. 10 males (INPA) and 2 females (INPA), BRAZIL, Ceará, Ubajara. Parque Nacional de Ubajara, Rio Cafundó, pouco acima da cachoeira, Maximum Elevation: 795m. 350'13"S: 4054'35"W, 13.ii.2013, Malaise trap. Rafael, J.A; Limeira-de-Oliveira, F; Takiya, D.M; Santos, A.P.M.

\section{Acknowledgments}

NSR, AMSN and JAR thank Instituto Nacional de Pesquisas da Amazônia (INPA) for research support. NSR thanks the support for the Capes-INPA research grant. AMSN thanks particularly the CapesINPA research grant (Process: 88887.312051/2018-00). JAR thanks the support for the Cnpq research grant (Process: 300.997/2016-7). This study was financed in part by the Coordenação de Aperfeiçoamento de Pessoal de Nível Superior - Brasil (CAPES) - Finance Code 001" and by the Fundação de Amparo à Pesquisa do Estado do Amazonas (FAPEAM) - POSGRAD/scholarship/ financial support".

\section{Author's Contributions}

NSR and AMSN identified the species, prepared the figures. NSR, AMSN and JAR wrote the manuscript.

\section{References}

Silva-Neto, A. M.; García Aldrete, A. N.; Rafael, J. A. (2016) A Storage Method for "Psocoptera" (Insecta: Psocodea) in "CD Box". Entomobrasilis, 9: 220-223. doi: 10.12741/ebrasilis.v9i3.656

Silva-Neto, A. M.; García Aldrete, A. N; Rafael, J. A. (2019) New species of Euplocania Enderlein (Psocodea, 'Psocoptera', Ptiloneuridae) from Brazil, with a checklist of all known species of the genus. Zootaxa, 4550 (3): 374-390. doi: 10.11646/zootaxa.4550.3.5

Silva-Neto, A. M.; García Aldrete, A. N. (2020) A checklist of 'Psocoptera' (Psocodea) from Brazil: an update to the list of 2009 of Garcia Aldrete and Mockford, with an identification key to the families. Papéis Avulsos de Zoologia, 60: 1-14. doi: 10.11606/18070205/2020.60.29 